\title{
Influence of Diabetes and Hemodialysis Against Nerve Conduction Studies
}

Yoshikane Kato $^{1}$, Hiroshi Bando ${ }^{2}$, Tomomi Fujikawa ${ }^{1}$, Miyuki Narutaki ${ }^{1}$, Masami Yamamoto ${ }^{1}$, Hideki Kakutani ${ }^{1}$, Yujiro Shirai ${ }^{1}$, Kazuyo Ishikura ${ }^{1}$, Kazuhiro Kusunoki $^{1}$, Saeri Tanaka ${ }^{1}$, Takafumi Kawata ${ }^{1}$, Setsuko Kanazawa ${ }^{1}$, Sayuri Matsuzaki ${ }^{1}$, Masahiro Bando ${ }^{3}$ and Shinnichi Waka ${ }^{1}$

${ }^{1}$ Kanaiso Hospital, Tokushima, Japan

${ }^{2}$ Tokushima University / Medical Research, Tokushima, Japan

${ }^{3}$ Department of Nutrition and Metabolism, Institute of Biomedical Sciences, Tokushima University Graduate School, Tokushima, Japan

*Corresponding author: Hiroshi Bando, Tokushima University /Medical Research, Nakashowa 1-61, Tokushima 7700943 Japan, Tel: 819031872485, Fax: 81886031030, E-mail: pianomed@bronze.ocn.ne.jp

Received date: December 04, 2017; Accepted date: December 11, 2017; Published date: December 18, 2017

Copyright: (c) 2017 Kato Y. This is an open-access article distributed under the terms of the Creative Commons Attribution License, which permits unrestricted use, distribution, and reproduction in any medium, provided the original author and source are credited.

\begin{abstract}
Background: Diabetic peripheral neuropathy (DPN) has been prevalent and discussed, and nerve conduction studies (NCS) has been continued. We have checked NCS using recently introduced useful DPN-Check device.

Subjects and Methods: The subjects were 66 patients (pts) classified into 4 groups according to existence of diabetes mellitus (DM) and hemodialysis (HD); Group1: DM (+), HD (+) in 15 pts, group 2: DM (-), HD (+) in 15 pts, group 3: DM (+), HD (-) in 20 pts, group 4: 16 healthy controls. Methods included measurements of sural nerve conduction velocity (SNCV) and sural nerve action potential (SNAP) using HDN-1000.

Results: Average age in each group was 64.4 years to 72.6 years. SNCV value of 4 group in average was 37.1 $\mathrm{m} / \mathrm{sec}, 46.3 \mathrm{~m} / \mathrm{sec}, 49.3 \mathrm{~m} / \mathrm{sec}, 53.2 \mathrm{~m} / \mathrm{sec}$, respectively, and value of group 1 was significantly lower than those of group 2,3,4 ( $p<0.01)$. Similarly, average SNAP was $4.1 \mu \mathrm{V}, 8.7 \mu \mathrm{V}, 8.0 \mu \mathrm{V}, 21.6 \mu \mathrm{V}$, respectively, and group 1,2,3 were significantly lower than group $4(p<0.01)$. There was significant correlation between SNCV and SNAP in all subjects $(p<0.01)$. Significant correlations were shown between DM duration and SNCV, and DM duration and SNAP $(p<0.01)$.

Discussion and Conclusion: SNCV and SNAP were measured successfully and easily by HDN-1000, indicating clinical availability. Obtained data suggested that 1) SNCV is not significantly decreased due to only uremic neuropathy, 2) SNCV is significantly decreased in patients with both HD and DM, 3) SNAP is significantly decreased in patents with DM for years and 4) SNAP would be remarkably decreased when HD is in addition to DM. These results would become the basal data of future NCS for DM and HD.
\end{abstract}

Keywords: Diabetic peripheral neuropathy; Nerve conduction studies; Sural nerve conduction velocity; Sural nerve action potential; Diabetes mellitus; Hemodialysis

Abbreviations: DPN: Diabetic Peripheral Neuropathy; NCS: Nerve Conduction Studies; SNCV: Sural Nerve Conduction Velocity; SNAP: Sural Nerve Action Potential; DM: Diabetes Mellitus; HD: Hemodialysis; UN: Uremic Neuropathy; LCD: Low Carbohydrate Diet; CCM: Corneal Confocal Microscopy; IENFD: Intra-Epidermal Nerve Fiber Density; CTS: Carpal Tunnel Syndrome; MN: Median Neuropathy

\section{Introduction}

Diabetes mellitus (DM) has been increasing worldwide. The prevalence of the diabetics is $8.8 \%$ in 2015 , and it will rise to $10.4 \%$ in $2040[1,2]$. Neuropathy is one of common and important microangiopathic complication, and observed in high percentage of diabetic patients $[3,4]$. Historically speaking, diabetic peripheral neuropathy (DPN) has been widely known and prevalent. In order to clarify the influence of hyperglycemia on the progression of diabetic neuropathy, nerve conduction velocity was formerly measured at median, peroneal and tibial motor nerves, supporting the hypothesis of a metabolic component to diabetic neuropathy [5,6]. DPN has been actually diagnosed based on medical history, physical exam and some simple tests [6,7]. While this testing is easy to perform, it is limited in terms of its accuracy. Nerve conduction studies (NCS) has been introduced, but its complexity and cost have excluded their use in a routine evaluation $[8,9]$. Recently, advances in technology have enabled us to perform NCS easily. By sural nerve in calf and ankle, simple and useful DPNCheck device showed accurate NCS for the assessment of DPN $[10,11]$. Authors have reported lots of studies for years concerning diabetes including low carbohydrate diet (LCD), lipid metabolism, exercise, and ketone bodies [12-15]. In current study, we investigated NCS in patients with DM and/or with chronic hemodialysis (HD).

\section{Subjects and Methods}

We enrolled 66 subjects in current study, including 50 patients and 16 normal healthy subjects. Subjects were categorized into 4 groups according to the existence of DM and/or on hemodialysis (HD). The groups were as follows. Group 1 includes 15 diabetic patients with HD, group 2 includes 15 patients with $\mathrm{HD}$ and without DM, group 3 includes 20 diabetic patients without HD and group 4 includes 16 normal subjects which age were matched to that of group 3 (Table 1). Methods include the measurement of sural nerve conduction velocity 
Citation: Kato Y, Bando H, Fujikawa T, Narutaki M, Yamamoto M, et al. (2017) Influence of Diabetes and Hemodialysis Against Nerve

Page 2 of 5

(SNCV) and sural nerve action potential (SNAP) in the lower calf and ankle. We used recently introduced simple and precise medical device, HDN-1000 which was developed by NeuroMetrics Inc., USA with registered No. 226AABZI00091000. This device has been based on validated technologies [16,17], and has lots of research results with high sensitivity and reproducibility, and clinically simple and useful measurements $[18,19]$. The procedure on the examination is simple and performed within a few minutes. The small device gives electrical stimulation on the back side of the ankle, and can measure with a biosensor installed $9.22 \mathrm{~cm}$ ahead of the stimulation probe. The standard normal range has been adequate from various research, which were more than $48 \mathrm{~m} / \mathrm{sec}$ for the SNCV, and more than $6 \mu \mathrm{V}$ for SNAP $[8,11,20]$.

\section{Statistical analyses}

In current study, obtained data was shown as the mean \pm standard deviation (SD) and also median, quartile of $25 \%$ and $75 \%$ in biomarkers. For statistical analyses, correlation coefficients were calculated using Pearson or Spearman test of the Microsoft Excel analytical tool, which is Four steps Excel Statistics 4th edition [21]. Intergroup comparisons were made using the Wilcoxon rank sum test or the Bonferroni multiple comparisons (Lambert method). A significance level of less than $5 \%$ obtained using a two-tailed test was considered to be statistically significant.

\section{Results}

\section{Subjects of 4 groups}

The data of 66 subjects were shown in Table 1. Average age in each group was 64.4 years to 72.6 years Median DM duration was 23.5 years and 14.8 years in Group 1 and 3, and median HD duration was 6.0 years and 8.6 years in Group 1 and 2, respectively. When calculated by mean \pm standard deviation, SNCV value in group 1 was significantly lower than those of group 2, 3, $4(\mathrm{p}<0.01)$. SNAP values in group $1,2,3$ were significantly lower than that of group $4(\mathrm{p}<0.01)$.

\begin{tabular}{|c|c|c|c|c|}
\hline & Group 1 & Group 2 & Group 3 & Group 4 \\
\hline \multicolumn{5}{|c|}{ Categorization from treatment } \\
\hline Diabetic treatment & + & - & + & - \\
\hline Hemodialysis treatment & + & + & - & - \\
\hline \multicolumn{5}{|l|}{ Subjects } \\
\hline number & 15 & 15 & 20 & 16 \\
\hline male/female & $7 / 8$ & $5 / 10$ & $9 / 11$ & $8 / 8$ \\
\hline average age (year) & 67.8 & 72.6 & 67.9 & 64.4 \\
\hline standard deviation & 6 & 6.9 & 15.9 & 14.6 \\
\hline median & 68 & 74 & 70.5 & 62 \\
\hline quartile $25 \%$ & 63 & 67 & 60.1 & 52.8 \\
\hline qauartile $75 \%$ & 73.0 & 76.0 & 80.5 & 74.8 \\
\hline \multicolumn{5}{|c|}{ History of diabetes mellitus (year) } \\
\hline median & 23.5 & - & 14.8 & - \\
\hline
\end{tabular}

\begin{tabular}{|c|c|c|c|c|}
\hline quartile $25 \%$ & 13.3 & - & 6.6 & - \\
\hline qauartile $75 \%$ & 23.0 & - & 14.0 & - \\
\hline \multicolumn{5}{|c|}{ History of hemodialysis (year) } \\
\hline median & 6.0 & 8.6 & - & - \\
\hline quartile $25 \%$ & 3.1 & 5.9 & - & - \\
\hline qauartile $75 \%$ & 5.9 & 10.9 & - & - \\
\hline \multicolumn{5}{|c|}{ SN conduction velocity $(\mathrm{m} / \mathrm{sec})$} \\
\hline average & $37.1^{\mathrm{a}}$ & 46.3 & 49.3 & 53.2 \\
\hline standard deviation & 14.5 & 10.6 & 3.6 & 3 \\
\hline median & 38 & 49 & 49.5 & 53.5 \\
\hline quartile $25 \%$ & 22 & 45.5 & 47 & 50.8 \\
\hline qauartile $75 \%$ & 51 & 53 & 52 & 56 \\
\hline \multicolumn{5}{|c|}{$\mathrm{SN}$ action potential $(\mu \mathrm{V})$} \\
\hline average & $4.1^{\mathrm{b}}$ & $8.7^{\mathrm{b}}$ & $8.1^{b}$ & 20.6 \\
\hline standard deviation & 2.4 & 5.3 & 4.9 & 5.5 \\
\hline median & 3 & 9 & 6.5 & 21.5 \\
\hline quartile $25 \%$ & 2 & 3 & 4 & 18.5 \\
\hline qauartile $75 \%$ & 5.5 & 11.5 & 11.3 & 24.3 \\
\hline \multicolumn{5}{|c|}{$\begin{array}{l}\text { a Value of group } 1 \text { is significantly lower than that of group } 2,3,4(p<0.01) \text {; } \\
\text { b Value of group } 1,2,3 \text { is significantly lower than that of group } 4(p<0.01)\end{array}$} \\
\hline
\end{tabular}

Table 1: Classification and general data of the subjects.

\section{Correlation between SNCV and SNAP}

Correlation between SNCV and SNAP was shown in Figure 1. This includes all data from 4 groups. Both revealed significant correlation and data from each group showed close distribution, respectively.

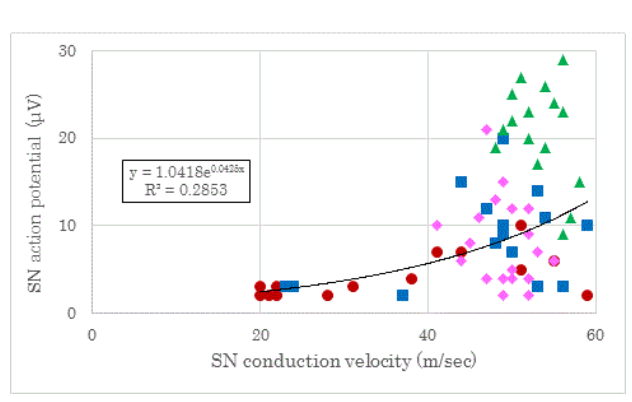

Figure 1: Correlation between sural nerve conduction velocity (SNCV) and sural nerve action potential (SNAP); Group 1: DM (+), HD (+); Group 2: DM (-), HD (+); Group 3: DM (+), HD (-); Group 4: DM (-), HD (-).

\section{Correlation between DM duration and NCS}

Correlation between diabetic duration and SNCV or SNAP was shown in Figure 2a and 2b. 
Citation: Kato Y, Bando H, Fujikawa T, Narutaki M, Yamamoto M, et al. (2017) Influence of Diabetes and Hemodialysis Against Nerve

It showed significant correlation between both biomarkers $(\mathrm{p}<0.01)$.
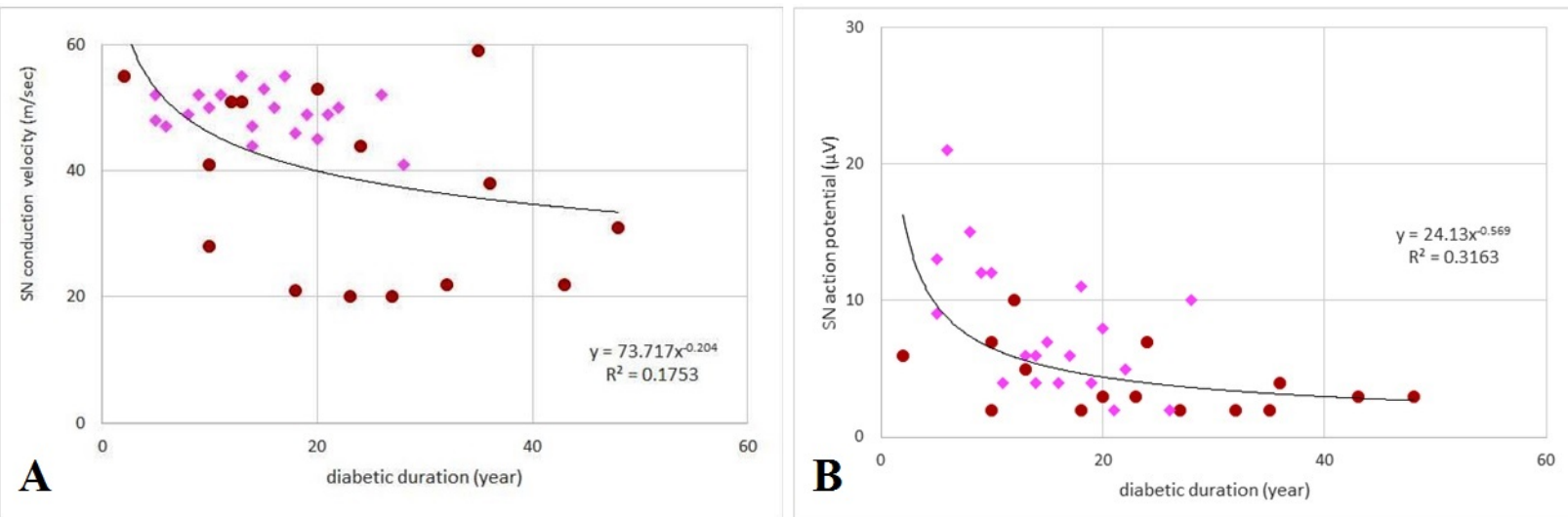

Figure 2: Correlation between diabetic duration and NCS; 2a DM duration and SNCV; Fig 2b DM duration and SNAP; Group 1: DM (+), HD (+); Group 3: DM (+), HD (-).

\section{Correlation between HD duration and NCS}

Correlation between HD duration and SNCV or SNAP was shown There was no significant correlation in each analysis. in Figure 3a and 3b.
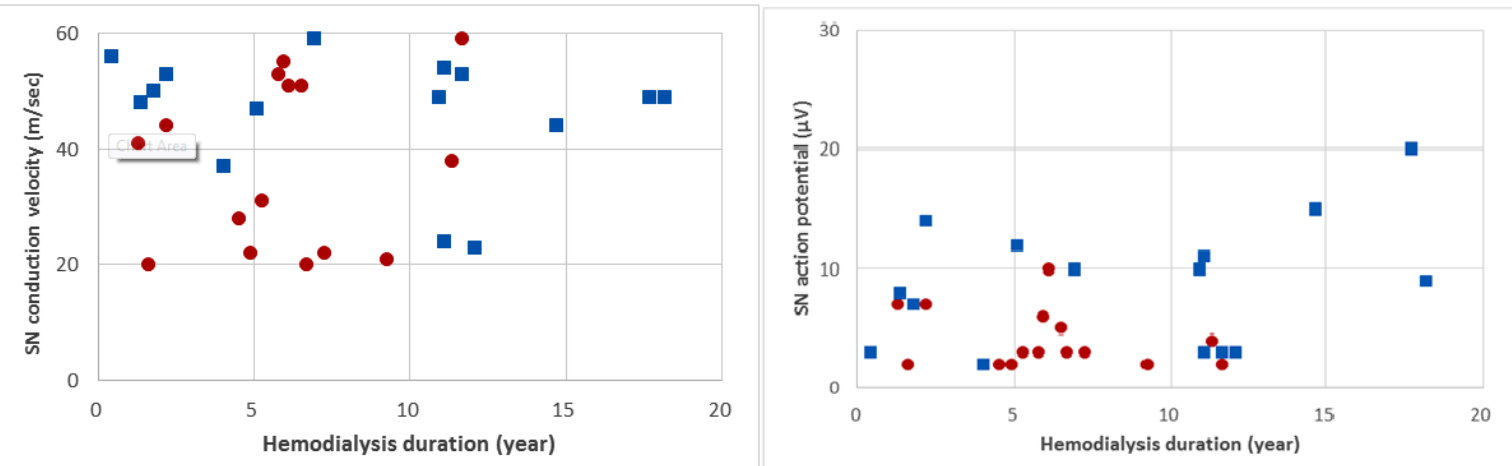

Figure 3: Correlation between hemodialysis duration and NCS; 3a-HD duration and SNCV; 3b-HD duration and SNAP; Group 1: DM (+), HD (+); Group 2: DM (-), HD (+).

\section{Discussion}

Formerly, there was a relationship between cardiac autonomic neuropathy and coronary artery disease [22-24]. Additional studies revealed a relationship between peripheral neuropathy and coronary artery disease [24-26].

The relationship between the presence of neuropathy were assessed by NCS and future mortality in diabetic patients [27,28]. Mortality were increased when a patient had neuropathic history and higher initial A1C, in which neuropathic history nearly doubled the mortality risk [hazard ratio of 1.95 ] whereas an $\mathrm{AlC}$ of $>8.5 \%$ had 1.64 hazard ratio [27]. Adjusted for other common risk factors, the hazard from neuropathy for all-cause mortality was 4.44 and for diabetes-related mortality were 11.82 . Consequently, neuropathy increased the risk of diabetes-related mortality more than 10 -fold when corrected for other risk factors [28].
According to the MONICA/KORA Augsburg Surveys, the prevalence of polyneuropathy was $28.0 \%$ in the diabetic subjects, $13.0 \%$ in impaired glucose tolerance (IGT), $11.3 \%$ in impaired fasting glucose (IFG), and 7.4\% in normal glucose tolerance (NGT) [25].

Sural nerve is one of a distal sensory nerve. It innervates at lateral and posterior third of leg and lateral aspect of foot and heel and lateral portion of the ankle. The characteristic point is that sural nerve is sensitive to DPN, which is recognized as a biomarker of DPN. [20,29].

In recent years, a new device of HDN-1000 was released, which can measure the nerve conduction velocity of the sural nerve easily. As to the results of SNCV and SNAP by HDN-1000, both showed nearly equivalent numerical values as compared with the conventional NCT, and their usefulness has been evaluated [11]. It included lots of research results based on validated technologies $[8,16,17,30]$. 
Page 4 of 5

Clinical data were summarized as follows: 1) sural nerve conduction is a standard, quantitative biomarker of DPN [8], 2) DPN was detected to be with high diagnostic sensitivity [7], 3) it showed abnormalities indicative of subclinical DPN [18], it correlated to morphological severity of DPN $[3,7,30], 4)$ detectable sural response was suggestive of low foot ulcer risk [31] and 5) predictive of concurrent micro vascular complications [32].

In clinical application of HDN-1000, it was convenient for repeated peripheral nerve function measurements, as well as reduced invasiveness and stress to the patient [19].

As to diabetic neuropathy, it has been known that carpal tunnel syndrome (CTS) frequently occurs in diabetic patients [33,34]. Its characteristics are that many cases are pointed out as median neuropathy (MN) at the wrist in asymptomatic NCS. MN is frequently observed in early stages when DPN was not observed, then it may be regarded as an early lesion of DPN [35].

There are remarkable decrease of SNAP in group 1 and 3 compared with that of group 4. One of the reasons for decreased SNAP in diabetics would be from decreased intra-epidermal nerve fiber density (IENFD) [36]. IENFD can be observed with a confocal microscope, by a $3 \mathrm{~mm}$ diameter punching needle biopsies at $10 \mathrm{~cm}$ above the ankle of the lower extremity with fixes and immunostaining. The value of IENFD falls from the early stage of DPN and declines in correlation with the progression of stage [37].

In previous reports, peripheral neuropathy in HD patients has been a devastating uremic complication which causes debilitating pain and limitation of movement [38]. Out of $28 \mathrm{HD}$ patients with 31 months duration of $\mathrm{HD}$ in median, 8 patients $(29 \%)$ were diabetics, and all patients exhibited overt peripheral neuropathy [38].

As another report, severe uremic neuropathy (UN) was seen in $16.4 \%$ of HD by both the Michigan Neuropathy Score Instrument (MNSI) and the electroneurographic (ENG) lower limbs examination [39]. End-stage renal failure in DM is often associated with severe distal motor and sensory deficits [40]. Peripheral neuropathy in patients with DM and HD may be correlated with hyperkalaemia and nerve dysfunction deterioration [41].

In current study, results were revealed that SNCV in group 1 was significantly lower than that of group 2, 3 and SNAP in group 1 and 2 were significantly decreased compared with that of group 4 . Taking our data and previous reports into consideration, it is suggested that 1 ) SNCV is not significantly decreased due to only uremic neuropathy, 2) SNCV is significantly decreased in patients with both HD and DM, 3) SNAP is significantly decreased in patents with DM for years and 4) SNAP would be decreased more when HD is in addition to DM. On contrast, there is limitation of study because of small number of subjects and affecting various influences of biomarkers.

\section{Conclusion}

In this study, decreased SNCV and SNAP were shown in patients with diabetes and/or with chronic hemodialysis. The data may suggest the pathophysiological influence of DM and HD for deterioration of neuropathy. These results would become the basal data of future investigation for NCS for DM and HD.

\section{Ethical Considerations}

Current study was conducted in compliance with the ethical principles of the Declaration of Helsinki and Japan's Act on the Protection of Personal Information along with the Ministerial Ordinance on Good Clinical Practice (GCP) for Drug (Ordinance of Ministry of Health and Welfare No. 28 of March 27, 1997). No ethical committee meeting was held. Informed consent was obtained from the subjects.

\section{References:}

1. Ogurtsova K, da Rocha Fernandes JD, Huang Y, Linnenkamp U, Guariguata L, et al. (2017) IDF Diabetes Atlas: Global estimates for the prevalence of diabetes for 2015 and 2040. Diabetes Res Clin Pract 128: 40-50.

2. International Diabetes Federation (IDF) (2015) Standards of medical care in diabetes-2015. Diabetes Care 38: S1-S94.

3. Dyck P, Kratz K, Karnes J, Litchy W, Klein R, et al. (1993) The Prevalence By Staged Severity Of Various Types Of Diabetic Neuropathy, Retinopathy, And Nephropathy In A Population-Based Cohort. Neurology 43: 817-824.

4. Boulton A (2005) Management Of Diabetic Peripheral Neuropathy. Clinical Diabetes 23: 9-15.

5. Graf RJ, Halter JB, Pfeifer MA, Halar E, Brozovich F, et al. (1981) Glycemic control and nerve conduction abnormalities in non-insulindependent diabetic subjects. Ann Intern Med 94: 307-311.

6. Vinik AI (1999) Diabetic neuropathy: pathogensis and therapy. Am J Med. 107:17S-26S.

7. Dyck PJ, Karnes JL, Daube J, O'Brien P, Service FJ (1985) Clinical and neuropathological criteria for the diagnosis and staging of diabetic polyneuropathy. Brain. 108: 861-880.

8. England JD, Gronseth GS, Franklin G, Miller RG, Asbury AK, et al. (2005) Distal symmetrical polyneuropathy: Definition for clinical research. Muscle Nerve 31: 113-123.

9. Tesfaye S, Malik R, Boulton A, Spallone V, Dyck P, et al. (2010) Diabetic Neuropathies: Update On Definitions, Diagnostic Criteria, Estimation Of Severity, And Treatments. Diabetes Care 33:2285-2293.

10. Weisman A, Bril V, Ngo M, Lovblom L, Halpern E, et al. (2013) Identification And Prediction Of Diabetic Sensorimotor Polyneuropathy Using Individual And Simple Combination Of Nerve Conduction Study Parameters. Plos One 8: E58783.

11. Lee JA, Halpern EM, Lovblom LE, Yeung E, Bril V, et al. (2014) Reliability and Validity of a Point-of-Care Sural Nerve Conduction Device for Identification of Diabetic Neuropathy. PLoS ONE 9: e86515.

12. Bando H, Nakamura T, Yonei Y, Takenaka Y, Seki K (2015) Lipid profile of masters athletes in ice-skating, a model of anti-aging research Glycative stress research 2: 52-57.

13. Muneta T, Kawaguchi E, Nagai Y, Matsumoto M, Ebe K, et al. (2016) Ketone body elevation in placenta, umbilical cord, newborn and mother in normal delivery. Glycative Stress Research 3: 133-140.

14. Ebe K, Bando H, Muneta T, Bando M, Yonei Y (2017) Effect of low carbohydrate diet (LCD) for diabetic patients with hypertriglycemia. Endocrinol Metab. 1:104.

15. Bando H, Ebe K, Muneta T, Bando M, Yonei Y (2017) Investigation of uric acid and cystatin $\mathrm{C}$ on low-carbohydrate diet (LCD). Diabetes Res Open J 3: 31-38.

16. Kong X, Lesser EA, Potts FA, Gozani SN (2008) Utilization of nerve conduction studies for the diagnosis of polyneuropathy in patients with diabetes: a retrospective analysis of a large patient series. J Diabetes Sci Technol 2: 268-274.

17. Pambianco G, Costacou T, Strotmeyer E, Orchard TJ (2011) Risk factor associations with clinical distal symmetrical polyneuropathy and various neuropathy screening instruments and protocols in type 1 diabetes. Diabetes Res Clin Pract 91: 15-20. 
Citation: Kato Y, Bando H, Fujikawa T, Narutaki M, Yamamoto M, et al. (2017) Influence of Diabetes and Hemodialysis Against Nerve Conduction Studies. J Gen Pract (Los Angel) 5: 343. doi:10.4172/2329-9126.1000343

Page 5 of 5

18. Albers JW, Herman WH, Pop-Busui R, Martin CL, Cleary P, et al. (2007) Subclinical neuropathy among Diabetes Control and Complications Tria participants without diagnosable neuropathy at trial completion: possible predictors of incident neuropathy? Diabetes Care. 30: 2613-2618.

19. Takase T, Miyoshi H, Kameda R, Edagawa S, Oita M, Omori K (2016) Improved neurological function with short-term glycemic intervention control in diabetes patients. Diabetes Frontier Online 3: e1-004.

20. Vinik AI, Bril V, Litchy WJ, Price KL, Bastyr EJ (2005) MBBQ Study Group Sural sensory action potential identifies diabetic peripheral neuropathy responders to therapy. Muscle \& Nerve 32: 619-625.

21. Yanai H (2015) Four step excel statistics, 4th Edition, Seiun-sha Publishing Co.Ltd, Tokyo, Japan.

22. Maser RE, Mitchell BD, Vinik AI, Freeman R (2003) The association between cardiovascular autonomic neuropathy and mortality in individuals with diabetes: a meta-analysis. Diabetes Care 26: 1895-1901.

23. Vinik AI, Maser RE, Mitchell BD (2003) Diabetic autonomic neuropathy. Diabetes Care 26: 1553-1579.

24. Ziegler D, Zentai CP, Perz S, Rathmann W, Haastert B, et al. (2008) Prediction of mortality using measures of cardiac autonomic dysfunction in the diabetic and nondiabetic population: The MONICA/KORA Augsburg Cohort Study. Diabetes Care 31: 556-561.

25. Elliott, J, Tesfaye S, Chaturvedi N, Gandhi RA, Stevens LK, et al. (2009) EURODIAB Prospective Complications Study Group. Large-fiber dysfunction in diabetic peripheral neuropathy is predicted by cardiovascular risk factors. Diabetes Care. 32: 1896-900.

26. Ziegler D, Rathmann W, Dickhaus T, Meisinger C, Mielck A (2008) Prevalence of polyneuropathy in pre-diabetes and diabetes is associated with abdominal obesity and macroangiopathy: The MONICA/KORA Augsburg Surveys S2 and S3. Diabetes Care 31: 464-469.

27. Calles-Escandon J, Lovato LC, Simons-Morton DG, Kendall DM, PopBusui R, et al. (2010) Effect of intensive compared with standard glycemia treatment strategies on mortality by baseline subgroup characteristics: the Action to Control Cardiovascular Risk in Diabetes (ACCORD) trial. Diabetes Care 33: 721-727.

28. Hsu WC, Chiu SY, Yen AM, Chen LS, Fann CY, et al. (2012) Somatic neuropathy is an independent predictor of all- and diabetes-related mortality in type 2 diabetic patients: a population-based 5-year follow-up study (KCIS No. 29). Eur J Neurol. 19:1192-1198.

29. American Diabetes Association (ADA) (2012) Standards of medical care in diabetes-2012. Diabetes Care, 35: S11-63.
30. Perkins BA, Orszag A, Grewal J, Ng E, Ngo M, et al. (2008) Multi-site testing with a point-of-care nerve conduction device can be used in an algorithm to diagnose diabetic sensorimotor polyneuropathy. Diabetes Care 31: 522-524.

31. Kiziltan ME, Gunduz A, Kiziltan G, Akalin MA, Uzun N (2007) Peripheral neuropathy in patients with diabetic foot ulcers: clinical and nerve conduction study. J Neurol Sci 258: 75-79.

32. Charles M, Soedamah-Muthu SS, Tesfaye S, Fuller JH, Arezzo JC, et al. (2010) EURODIAB Prospective Complications Study Investigators. Low peripheral nerve conduction velocities and amplitudes are strongly related to diabetic microvascular complications in type 1 diabetes: the EURODIAB Prospective Complications Study. Diabetes Care 33: 2648-2653.

33. Gazioglu S, Boz C, Cakmak VA (2011) Electrodiagnosis of carpal tunnel syndrome in patients with diabetic polyneuropathy. Clin Neurophysiol 122: 1463-1469.

34. Jeong DH, Kim CH (2014) The quantitative relationship between physical examinations and the nerve conduction of the carpal tunnel syndrome in patients with and without a diabetic polyneuropathy. Ann Rehabil Med. 38: $57-63$.

35. Horinouchi S, Deguchi T, Arimura K, Arimura A, Dochi Y, et al. (2014) Median neuropathy at the wrist as an early manifestation of diabetic neuropathy. J Diabetes Investig. 5: 709-713.

36. Yagihashi S (2011) Recent advances in clinical practice and in basic research on diabetic neuropathy. Brain and Nerve 63: 571-582.

37. Arimura A, Deguchi T, Sugimoto K, Uto T, Nakamura T, et al. (2013) Intraepidermal nerve fiber density and nerve conduction study parameters correlate with clinical staging of diabetic polyneuropathy. Diabetes Res Clin Pract. 99: 24-29.

38. Strempska B, Bilinska M, Weyde W, Koszewicz M, Madziarska K, et al. (2013) The effect of high-tone external muscle stimulation on symptoms and electrophysiological parameters of uremic peripheral neuropathy. Clin Nephrol 79: S24-27.

39. Mambelli E, Barrella M, Facchini MG, Mancini E, Sicuso C, et al. (2012) The prevalence of peripheral neuropathy in hemodialysis patients. Clin Nephrol 77: 468-475.

40. Said G (2013) Uremic neuropathy. Handb Clin Neurol. 115: 607-612.

41. Arnold R, Kwai NC, Krishnan AV (2013) Mechanisms of axonal dysfunction in diabetic and uraemic neuropathies. Clin Neurophysiol 124: $2079-2090$ 